\title{
Illness Perception Predicting Cardiovascular Health Behaviors among Patients with Ischemic Heart Disease in Nepal: A Descriptive Cross- sectional Study
}

\author{
Punam Gauro,' Ploenpit Thaniwattananon, 'Charuwan Kritpracha' \\ 'Faculty of Nursing, Prince of Songkhla University, Hatyai, Thailand.
}

ABSTRACT

Introduction: Cardiovascular health behaviors refer to the activities done by individuals to prevent recurrence, minimize risk factors, improve survival, reduce recurrent events, control cardiovascular disease, and help prevent further complications. Illness perception may determine these behaviors. This study is aimed to identify level of illness perception, cardiovascular health behaviors and illness perception predicting cardiovascular health behaviors among patients with ischemic heart disease.

Methods: The study was a descriptive cross-sectional study. Altogether 114 samples were selected using convenience sampling technique. Data was collected by using pretested semi-structured questionnaire. The data were analyzed using descriptive statistics.

Results: Illness perception was at moderate level $(\mathrm{M}=148.05, \mathrm{SD}=12.86)$ which represented a moderate threatening perception. The score of cardiovascular health behaviors was at a high level $(\mathrm{M}=92.14, \mathrm{SD}=10.72)$.

Conclusions: The findings showed that illness perception can be a predictor of cardiovascular health behaviors.

Keywords: cardiovascular health behaviors; illness perception; ischemic heart disease.

\section{INTRODUCTION}

Worldwide cardiovascular disease (CVD) is the leading cause of mortality. It has been reported that 17.9 million people died from CVD in 2016, constituting $31 \%$ of all global deaths ${ }^{1}$ and half of these is estimated to occur in Asia. ${ }^{2}$ Among CVD, ischemic heart disease (IHD) is one of the main causes of mortality. ${ }^{1}$

IIIness perception was also identified as a factor related to individual cardiovascular health behavior. ${ }^{3}$ Most patients with IHD have less knowledge about the importance of cardiovascular health behaviors to prevent recurrence of IHD. ${ }^{4}$ Thus, patients with diagnosed IHD remain at high risk for cardiac event reoccurrence. ${ }^{5}$ Each individual could intensely change their cardiovascular health behaviors according to their perception ${ }^{6}$ using systematic sampling, the first 6 patients with type 2 diabetes mellitus aged $>$ or $=18$ years who visited them for consultation during the study period. Data on 250 patients included patient illness perception assessment (Brief Illness Perception Questionnaire, IPQ).

Theexisting knowledge regarding illness perception and cardiovascular health behaviors among IHD patients is limited in Nepal. ${ }^{7}$ This study aimed to examine the level of illness perception, cardiovascular health behaviors, and illness perception predicting cardiovascular health behaviors among IHD patients.

\section{METHODS}

This is a descriptive cross-sectional study. This study was conducted in a public hospital (BP Koirala Institute of Health Sciences, Dharan) in Eastern Nepal from January to March 2018. Prior to the commencement of the study the researcher obtained approval from the Institutional Review Board (IRB), University of Thailand

Correspondence: Ms. Punam Gauro, Faculty of Nursing, Prince of Songkhla University, Hatyai, Thailand. Email: punam. gauro@gmail.com, Phone: +977-9841208597. 
Gauro et al. Illness Perception Predicting Cardiovascular Health Behaviors among Patients with Ischemic Heart Disease in Nepal...

and Nepal Health Research Council (Reference No 1672) and BPKIHS, Dharan. All the participants also gave their informed written consent. Common Sense Model (CSM) of illness perception proposed by Leventhal et al. ${ }^{8}$ is used as conceptual framework. Patients aged more than 18 years, able to communicate, understand Nepali language and diagnosed with stable IHD were included.

A convenience sampling method was used. The total participants were 114 outpatients. The sample size was calculated as below:

$\mathrm{n}=\mathrm{Z}^{2} \times \mathrm{p} \times(1-\mathrm{p}) / \mathrm{e}^{2}$

$=(1.64)^{2} \times 0.5 \times(1-0.5) /(0.1)^{2}=67$

Where,

$\mathrm{n}=$ required sample size

$\mathrm{Z}=$ Confidence Interval $(\mathrm{Cl}), 90 \%$

$\mathrm{p}=$ prevalence, $50 \%$

$\mathrm{e}=$ Margin of error, $10 \%$

Therefore, the calculated sample size was 67 . However the sample taken was 114 people diagnosed with IHD. The researcher collected data by interviewing with a standardizedinstrument. Theresearcheremployed three instruments: (1) Demographic Data and Health Related Information (DHI), (2) Illness Perception QuestionnaireRevised (IPQ-R), and (3) The Modified Cardiac Health Behaviors Scale (MCHBS). All the questionnaires were in English which were later translated into the Nepali language. Three experts validated the content validity of the instruments. Two experts from Prince of Songkla University and one from Nepal. The test-retest reliability was tested for IPQ-R and MCHBS.

Demographic Data and Health Related Information (DHI) was a self-constructed questionnaire. DHI includes age, gender, marital status, education, and occupation. IIIness perceptionwasmeasuredusing IIInessPerception Questionnaire-Revised developed by Moss-Morris. ${ }^{10}$ The cardiovascular health behavior scale was developed by Oh et al. ${ }^{11}$ Although the questionnaire is relevant to this study, some of the items are not specific. Therefore, the researcher modified the questionnaire to assess cardiac health behaviors based on the American Heart Association (AHA) guideline.

Data collected was be kept in Microsoft Excel and then edited and checked. After that the data will be put in SPSS, the descriptive statistical analysis was done to describe DHI. Frequency, percentages will be calculated for binary data and mean and standard deviation will be calculated for continuous data after the normality of the data has been checked.

RESULTS
The results from this study showed that participants were between the ages of 34 and $74(\mathrm{M}=52.84$, $\mathrm{SD}=8.24)$ and majority of the participants $45(39.5 \%)$ were in the 51 to 60 age group. More than half of the patients $67(58.8 \%)$ were male and most of them were Hindu 82 (55\%). Many patients 45 (39\%) completed a secondary level of education and only $9(7.9 \%)$ of the patients were unemployed. Majority of the patients 98 $(86 \%)$ were from extended family and two-thirds of the patients $80(70.1 \%)$ had a monthly income of 10,000 to 30,000 Nepalese rupees (NPR) (approx. 1 US dollars $=108$ Nepali rupees).

The mean body mass index (BMI) was $26.04 \mathrm{~kg} / \mathrm{m} 2$ $(S D=2.97)$ and the duration of illness in most of the patients $74(64.9 \%)$ with IHD in this study was more than 12 months. Majority of the patients 79 (69.2\%) had a history of smoking. Majority of the patients $100(87.7 \%)$ reported that hypertension was their comorbidity. Medications recently used by the patients were antihypertensive drugs, anticoagulants and aspirin, and antidiuretics in 10 (87.7\%), 88 (77.2\%), and $29(25.4 \%)$ of the patients respectively (Table 1$)$.

The total illness perception mean score among the patients with IHD was $\mathrm{M}=148.05$ ( $\mathrm{SD}=12.86)$

\begin{tabular}{|c|c|}
\hline Characteristics & n (\%) \\
\hline \multicolumn{2}{|c|}{$\begin{array}{l}\mathrm{BMI}, \mathrm{kg} / \mathrm{m}^{2}(\mathrm{M}=26.04, \mathrm{SD}=2.97, \mathrm{Min} \\
=18.03, \mathrm{Max}=33.69)\end{array}$} \\
\hline$<18.5$ (Underweight) & $1(0.9)$ \\
\hline 18.5-24.9 (Normal) & $43(38.7)$ \\
\hline 25-29.9 (Overweight) & $60(51.4)$ \\
\hline$\geq 30$ (Obese) & $10(9)$ \\
\hline \multicolumn{2}{|c|}{$\begin{array}{l}\text { Duration ( } M=3.32, S D=0.973, \text { Min }<1 \text {, } \\
\text { Max } \geq 12 \text { months) }\end{array}$} \\
\hline \multicolumn{2}{|c|}{$<1$} \\
\hline $1-6$ & $4(3.5)$ \\
\hline $7-12$ & $29(25.4)$ \\
\hline$>12$ & $7(6.1)$ \\
\hline \multicolumn{2}{|l|}{ History of Smoking } \\
\hline Smoker & $74(64.9)$ \\
\hline Non-smoker & $79(69.2)$ \\
\hline \multicolumn{2}{|l|}{ Comorbidity $^{\text {a }}$} \\
\hline Diabetes Mellitus & $35(30.8)$ \\
\hline Hypertension & $83(72.8)$ \\
\hline Others & $10(87.7)$ \\
\hline CA cervix & $1(0.9)$ \\
\hline Gastritis & $18(16.2)$ \\
\hline \multicolumn{2}{|l|}{ Medications used a } \\
\hline Antihypertensive & $10(87.7)$ \\
\hline Anticoagulant and aspirin & $88(77.2)$ \\
\hline Antidiabetic & $29(25.4)$ \\
\hline
\end{tabular}


Gauro et al. Illness Perception Predicting Cardiovascular Health Behaviors among Patients with Ischemic Heart Disease in Nepal...

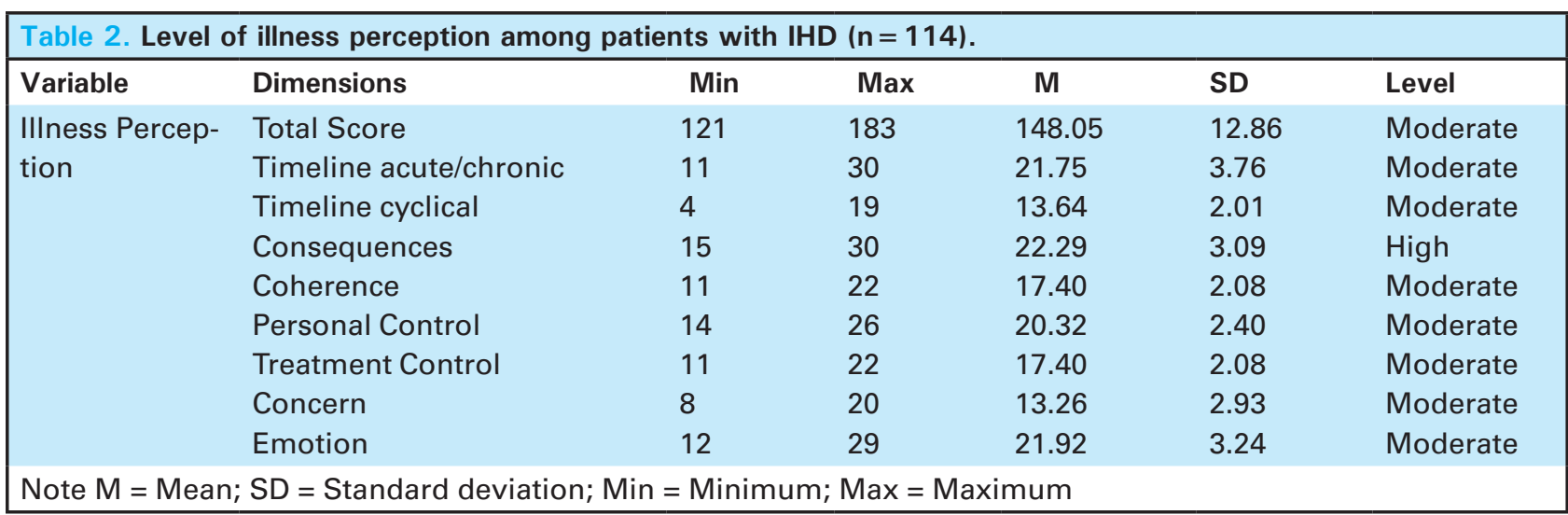

Note: aPatients provided more than one answer.

which indicated moderate threatening perception of the illness. The dimension consequences had the highest level $(M=22.29, \quad S D=3.09)$. Other dimensions reported moderate levels which were timeline acute/ chronic $(M=21.75, S D=3.76)$, timeline cyclical $(M=$ 13.64, $S D=2.01)$, concern $(M=13.26, S D=2.93)$, personal control $(M=20.32, S D=2.40)$, treatment control $(M=17.40, S D=2.08)$, emotion $(M=21.92$, $\mathrm{SD}=3.24)$, and coherence $(\mathrm{M}=17.40, \mathrm{SD}=2.08)$ (Table 2).

The perceived causes were smoking 62 (54.3\%), followed by diet 58 (50.8\%), stress 57 (50\%), ageing 48 $(42.10 \%)$, heredity 34 (28.07\%), alcohol 34 (28.07\%), hypertension $26(22.80 \%)$, physical inactivity 26 (22.80\%), and diabetes mellitus 10 (8.77\%) (Table 3).

\begin{tabular}{|ll|}
\hline \multicolumn{2}{|l|}{ Table 3. Perceived causes by IHD patients $(\mathbf{n}=\mathbf{1 1 4})}$. \\
\hline Causes & $\mathbf{n}(\%)$ \\
Smoking & $62(54.3)$ \\
Diet & $58(50.8)$ \\
Stress & $57(50)$ \\
Ageing & $48(42.1)$ \\
Heredity & $34(28.1)$ \\
Alcohol & $34(28.1)$ \\
Hypertension & $26(22.8)$ \\
Physical inactivity & $26(22.8)$ \\
Diabetes Mellitus & $10(8.8)$ \\
\hline
\end{tabular}

Participants reportedahighlevelofcardiovascularhealth behaviors $(M=92.14, S D=10.72)$. The dimensions of cardiovascular health behaviors in IHD patients were reported at high levels of taking medications $(M=$ 11.60, $\mathrm{SD}=0.72)$ and blood pressure control $(\mathrm{M}=$ 15.73, SD= 3.71). The dimensions of cardiovascular health behaviors that the patients reported to perform at moderate levels were diet management $(M=25.04$, $S D=4.12)$, physical activity $(M=13.72, S D=2.65)$, smoking cessation $(\mathrm{M}=11.61, \mathrm{SD}=3.52)$, and stress management $(M=11.04, S D=2.24)$ (Table 4).

\begin{tabular}{|lllllll|}
\hline Table 4. Level of cardiovascular health behaviors among patients with IHD (n=114). \\
\hline Variable & Dimensions & Min & Max & M & SD & Level \\
Cardiovascular & Total Score & 67 & 113 & 92.14 & 10.72 & High \\
Health Behaviors & Smoking Cessation & 8 & 16 & 11.61 & 3.52 & Moderate \\
& Diet management & 15 & 32 & 25.04 & 4.12 & Moderate \\
& Blood pressure control & 8 & 20 & 15.73 & 3.71 & High \\
& Physical activity & 5 & 20 & 13.72 & 2.65 & Moderate \\
& Stress management & 6 & 15 & 11.04 & 2.24 & Moderate \\
& Taking medications & 8 & 12 & 11.60 & 0.72 & High \\
Note M = Mean; SD = Standard deviation; Min = Minimum; Max = Maximum & & \\
\hline
\end{tabular}

\section{DISCUSSION}

The mean age of the patients in this study ranged between $50-60$ which is similar to previous studies. ${ }^{5}$ The majority of the IHD patients were male, which was similar to the previous studies on IHD that reported more male patients in Nepal ${ }^{12}$ and in a Jordanian study. ${ }^{5}$ In this study, the causes of IHD tended toward smoking as a lifestyle factor because majority of the participants perceived that smoking causes IHD. A previous study reported that smoking by more males than females was one of the factors reported to cause IHD. ${ }^{13}$ Majority of patients were hypertensive and most of them were overweight. It has been reported in previous study that hypertension was common among obese patients and could trigger IHD and it was also the major co-morbidity 
occurring in IHD patients. ${ }^{5}$

In this study majority of the patients perceived that the major causes of their disease IHDwere smoking, diet and stress. The causes were similar with previous studies. ${ }^{5}$ The level of cardiovascular health behaviors among IHD patients was high in this study. This indicated that the patients with IHD had high performance of cardiovascular health behaviors. The reason behind the high level of cardiovascular health behavior of IHD patients was possibly due to the early health education received by the patients and other counseling from health personnel on smoking cessation, diet, exercise, taking medicines on time, and stress management. As a result, they had better perception of their illness. Therefore, this made the patients aware of their health. One study revealed that training and education helped IHD patients for better health outcome. ${ }^{14}$

The high level of cardiovascular health behaviors was beneficial for the IHD patients, as this showed they were conscious and aware of their health conditions. The dimensions of cardiovascular health behaviors by the IHD patients were at a high level for taking medications and blood pressure control. One of the studies ${ }^{15}$ found that family and support from friends helped them changed their lifestyles and also resulted in changing the cardiovascular health behaviors. In Nepal, support from family members was one of the most important and strongest support systems for their whole lives.

This study found that diet management, physical activities, smoking cessation and stress management of the patient's behavior was at a moderate level. The IHD patients in Nepal perceived that many cultural practices might influence the management of diet in IHD patients to take different varieties of food which contain high calories. There are many festivals which influence the intake of high calorie food. ${ }^{7}$ One previous study had revealed that a positive attitude helped to improve cardiovascular health behaviors and prevented the risk. ${ }^{16}$

The relationship between illness perception and cardiovascular health behaviors among IHD patients in this study revealed a negative correlation with a significant level of 0.05 . This finding was in contrast with previous studies ${ }^{17}$ as they found positively significant association between illness perception and cardiovascular health behaviors. Likewise, previous studies on illness perception involving patients with other chronic disease, such as diabetes, asthma, and osteoarthritis, found that illness perception were strong predictors of cardiovascular health behaviors. ${ }^{18}$

There might be several reasons behind the negative relationship. Illness perception of the patients towards
IHD changed during rehabilitation following the first attack. ${ }^{19}$ These changes of illness perception were associated with the proper cardiovascular health behaviors which helped to prevent recurrence of IHD and enhanced their better health. ${ }^{19}$ Another study found that participating in cardiac rehabilitation (CR) could increase blood circulation and maintain the oxygen level that resulted in a significant increase in the functional heart capacity and a significant reduction in the heart rate. ${ }^{20}$ Knowledge of the illness and adjustment might have reduced the negative perception of illness and increased cardiovascular health behavior. The majority of the patients in this study were educated. Kang et al reported that persons with a higher education were more capable of understanding the necessity of changing their lifestyle which motivated them to perform cardiovascular health behaviors more often. ${ }^{4}$

Majority of the patients perceived illness identity as chest pain; breath lessens, and body discomfort. For these symptoms, the patients perceived to take good suggestions from the health care providers. The findings were similar with previous studies majority of the patients believed that IHD were due to smoking, diet and heredity. The findings were similar with previous study. ${ }^{5}$

The multiple regression analysis revealed that timeline acute/chronic, personal control, and concern were the statistically significant domains strongly predicting cardiovascular health behaviors. Similarly, another study found that personal control was a strong predictor of cardiovascular health behaviors. ${ }^{21}$ Timeline is one of the predictors of cardiovascular health behaviors in this study. The greater time period of diagnosis indicated thesepatientshave received moreinformation regarding their disease condition and cope with illness as well as performhighercardiovascularhealth behaviorstoadjust with disease. Similarly, personal control predicted cardiovascular health behaviors. The reason personal control could predict cardiovascular health behaviors might be because the majority of the IHD patients in this study were educated, and most of them were already rehabilitated. Limitation of the study was the use of convenient sampling technique during data collection that might reduce generalizability to the population.

\section{CONCLUSIONS}

The study indicated that perception of illness by the patient specially timeline acute or chronic, personal control and concern can predict cardiovascular health behavior. Thus, illness perception of the patient should be taken into consideration while providing education regarding modification of cardiovascular health behavior. This study will be beneficial for the development of knowledge by healthcare professionals 
to educate IHD patients especially on the misperception and role of illness perception on cardiovascular health behavior.

\section{ACKNOWLEDGEMENTS}

\section{Authors acknowledge Prince of Songkla University}

through Thailand Education Hub for ASEAN countries (TEC-AC) scholarships and BPKIHS, Dharan.

\section{Conflict of Interest: None.}

\section{REFERENCES}

1. World Health Organization. Cardiovascular diseases (CVDs) [Internet]. 2020 [Cited 2020 July 18]. Available from: www. who.int/news-room/fact-sheet/detail/cardiovasculardisease-(cvds) [Full Text]

2. Ohira T, Iso H. Cardiovascular disease epidemiology in Asia. Circulation J. 2013:7(7):1646-52. [Full Text]

3. Vilchinsky N, Dekel R, Asher Z, Leibowitz M, Mosseri M. The role of illness perceptions in the attachment-related process of affect regulation. Anxiety, Stress and Coping. 2013 May 1;26(3):314. [Full Text]

4. Kang Y, Yang IS, Kim N. Correlates of health behaviors in patients with coronary artery disease. Asian Nurs Res. 2010 Mar 1;4(1):45-55. [PubMed]

5. Mosleh, Sultan M., and Mona MA Almalik. Illness Perception and Adherence to Healthy Behaviour in Jordanian Coronary Heart Disease Patients. European Journal of Cardiovascular Nursing. 2016 June;4(15):223-230. [Full Text]

6. Petriček G, Vrcić-Keglević M, Vuletić G, Cerovečki V, Ožvačić $\mathrm{Z}$, Murgić L. Illness perception and cardiovascular risk factors in patients with type 2 diabetes: cross-sectional questionnaire study. Croatian Med J. 2009 Dec 15;50(6):583-93. [Full Text]

7. Oli N, Vaidya A, Subedi M, Krettek A. Experiences and perceptions about cause and prevention of cardiovascular disease among people with cardiometabolic conditions: findings of in-depth interviews from a peri-urban Nepalese community. Global health action. 2014 Dec 1;7(1):24023. [․ㅏll Text

8. Leventhal H, Meyer D, Neren Z. The common-sense representation of illness danger. Contrib to Med psycho. 1984;(2):7-30. [Full Text]

9. Green SB. How many subjects does it take to do a regression analysis.Multi.BehavRes. 1991 Jul 1;26(3):499-510. [PubMed]

10. Moss-Morris R, Weinman J, Petrie K., Horne R., Cameron $\mathrm{L}$, Buick D. The revised illness perception questionnaire (IPQ-R). Psycho and health. 2002 Jan 1;17(1):1-16. [Full Text]

11. Oh H, Moorhead SA, Ahn S, Song R. Development and Psychometric Tests of Cardiac Health Behavior Scale for Adults with Cardiovascular Risks [Internet]. 2020 [Cited 2020 July 18]. Available from: https://sigma.nursingrepository. org/handle /10755/303919 [Full Text]
12. Gurung RB, Pant P, Pokharel B, Koju R, Bedi TR. Review of Ischemic Heart Disease Patients admitted in Dhulikhel Hospital. NJH. 2010;7(1):1-4. [Full Text]

13. Saffi MA, Pokorski SC, Silva ER. Cardiovascular risk factors and evidence-based health education. Health Irvine. 2014;6:625-631. [Full Text]

14. Sararoudi RB, Motmaen M, Maracy MR, Pishghadam E, Kheirabadi GR. Efficacy of illness perception focused intervention on quality of life, anxiety, and depression in patients with myocardial infarction. J Res Med Sci. 2016;21. [PubMed | Full Text]

15. Murray J, Fenton G, Honey S, Bara AC, Hill KM, House A. A qualitative synthesis of factors influencing maintenance of lifestyle behaviour change in individuals with high cardiovascular risk. BMC CARDIOVASC DISOR. 2013 Dec;13(1):48. [Full Text]

16. Schneider S, Diehl K, Bock C, Herr R, Mayer M, Görig T. Modifying health behavior to prevent cardiovascular diseases: a nationwide survey among German primary care physicians. Int J Environ Res Public Health. 2014;11(4):4218-32. [PubMed]

17. Byrne M, Walsh J, Murphy AW. Secondary prevention of coronary heart disease: patient beliefs and health-related behaviour. J Psychosom Res. 2005 May 1;58(5):403-15. [PubMed]

18. Horne R, Weinman J. Self-regulation and self-management in asthma: exploring the role of illness perceptions and treatment beliefs in explaining non-adherence to preventer medication. Psychol Health. 2002 Jan 1;17(1):17-32. [Full Text]

19. Janssen V, De Gucht V, van Exel H. Changes in illness perception and Quality of Life During Participation in Cardiac Rehabilitation. Int J BehavMed. 2013;20:582-589. [PubMed]

20. Parvand M, Goosheh B, Sarmadi AR. Effect of cardiac rehabilitation on heart rate and functional capacity in patients after myocardial infarction. Iran Rehabil J. 2016 Sep 10;14(3):157-62. [Full Text]

21. Princip M, Scholz M, Meister-Langraf RE, Barth J, Schnyder U, Znoj H, Schmid JP, Thayer JF, von Känel R. Can illness perceptions predict lower heart rate variability following acute myocardial infarction? Front Psychol. 2016 Nov 18;7:1801. [Full Text]

This work is licensed under a Creative Commons Attribution 4.0 International License. The images or other third party material in this article are included in the article's Creative Commons license, unless indicated otherwise in the credit line; if the material is not included under the Creative Commons license, users will need to obtain permission from the license holder to reproduce the material. To view a copy of this license, visit http://creativecommons.org/licenses/by/4.0/ 